\title{
Load Frequency Control with Adaptive Fuzzy Logic Approach for Multi Area Power System
}

\author{
Pradeep Kumar Sahu ${ }^{1}$, Abhijeet Singh ${ }^{2}$ \\ ${ }^{1}$ M.Tech Scholar, Oriental College of Technology (RGPV), Bhopal, India \\ ${ }^{2}$ Professor, Oriental College of Technology (RGPV), Bhopal, India
}

\begin{abstract}
The dynamic performance of load frequency control of multi area power system is done by using Fuzzy logic controller. Change in frequency causes in speed. Thus, it is necessary to maintain network frequency constant so, that power system should run satisfactorily and in parallel various motor should run at a desired speed and correct time is obtained from synchronous clock in the system so, that device should run satisfactorily. Simulation result for the multi area power system proves the effectiveness of proposed LFC and shows its superiority over classical PID controller. The main objectives of load frequency controller in each area is to supply load demand and power transfer through tie lines to minimize transient deviations to ensure steady state errors to be zero and to maintain frequency to a particular specified limit. When dealing with load frequency problem of power system, that is unexpected external disturbances, parameters uncertainties pose big challenges for controller design. Thus, ADRC as an increasing popular practical control technique has an advantage of requiring the little information from the plant model and being robust against disturbances and uncertainties. The controller is constructed for a three area power system with different turbine units including nonreheat unit, reheat and hydraulic units in different areas.
\end{abstract}

Keywords: Load frequency control, fuzzy logic controller design of FL controller, Fuzzification Method

\section{Introduction}

In actual power system operations, the load is changing continuously and randomly, resulting in the deviations of load frequency and the tie-line power between any two areas from scheduled generation quantities. The aim of LFC is to regulate the frequency to the nominal value and to maintain the interchange power between control areas. The network frequency is maintained constant in order to run power systems in parallel operation and also operating various motors at desired speed in the system. In recent years, power system has more complicated and non-linear configuration. Therefore, tie-lines are used for various interconnected areas. Energy exchange between areas and inter area support during abnormal condition are provided through tie-lines .These tielines have been observed with power fluctuations which result in increased system capacity. Thus, load frequency control is more advanced controlled scheme which has been observed. In electrical power system, load-frequency (LF) control plays an important task for power system operation and design. Voltage and frequency controller are required to maintain generated power quality in order to supply constant voltage and frequency. Thus, the frequency is balanced or controlled by load-frequency controller. So many researches has been done over last few decades regarding loadfrequency control of single and multi area power system.

\section{Load Frequency Control}

Main function of load frequency is to ensure stable and reliable operation of power system. The PI controller is very simple for implementation and gives better dynamic response but their dynamic performance deteriorate when complexity in the system increases due to disturbances like load variation boiler dynamic problem. Thus, artificial intelligent controller like Fuzzy and neural control approaches are more suitable in this respect. Salient feature of these techniques is that they provide model free description of control system and do not require identical model. Literature survey shows that earlier work in the area of LFC pertains to interconnected thermal system and relatively lesser attention has been devoted to the LFC in multi area power system that is hydro thermal. Fuzzy logic offers better performance over conventional controller especially in complex and non-linearity. However it is demonstrated good dynamics only when selecting the specific membership function. In this paper, performance evaluation based on PI controller, Fuzzy logic controller and artificial neural controller for multi area control system is proposed. Thus, in this we are using Fuzzy logic technique for frequency load control where "Mamdani type" fuzzy inference system is used to find gains at different operating system.

\section{Fuzzy Logic Controller}

Fuzzy logic is used to design LFC. Generally, AFLC scheme is classified as direct and indirect. In direct, fuzzy logic system is used to generate control signal. And in indirect, fuzzy logic system is used to approximate unknown functions. Direct-indirect fuzzy logic FLC is proposed where, fuzzy logic system is employed for an each area due to unknown interconnections and unknown linearity due to GRC and GDB. To develop direct-indirect AFLC, fuzzy system having defuzzifier, product inference and singleton fuzzifier is considered. There are basically two types of fuzzy inference system and they are Mamdani inference system and sugeno type inference system. 


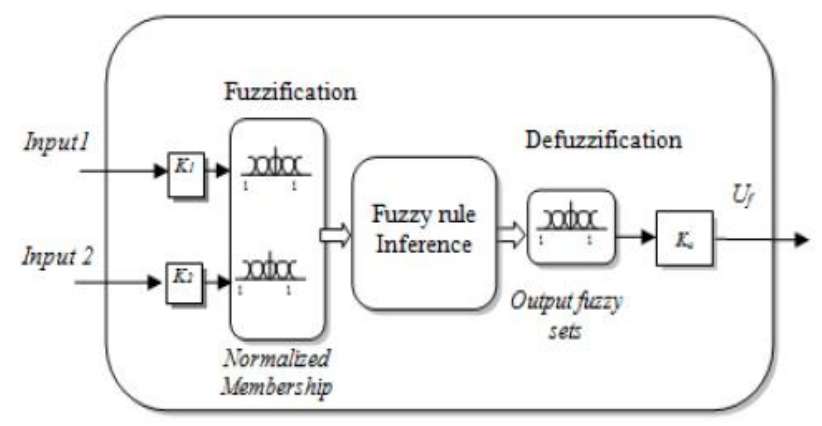

Figure 1: Basic structure of fuzzy controller

\section{Design of FL Controller}

Fuzzy logic controller's (FLC) are knowledge based controllers usually derived from a knowledge acquisition process or automatically synthesized from self-organizing control architecture. It typically defines a non-linear mapping from the system's state space to the control space.

The advantages of FLC's are, 1) Controller parameters can be changed very quickly by the system dynamics because no parameter estimation is required in designing controller for non-linear system. 2) It provides an efficient way of coping with imperfect information and offers flexibility in decision making process. The basic configuration of fuzzy logic based LFC composes the following components:

4.1 A fuzzification interface.

4.2 A knowledge base

4.3 A decision making logic and

4.4 A defuzzification interface.

The next step is to fuzzifying the input.The universe of discourse of the inputs is divided into seven fuzzy sets of triangular. The first block inside the controller is Fuzzification, which converts each piece of input data to degrees of membership by a lookup in one or several membership functions. The fuzzification block thus matches the input data with the conditions of the rules to determine how well the condition of each rule matches that particular input instance. There is a degree of membership for each linguistic term that applies to that input variable. Finally defuzzication is done to get required crisp output. The reverse of fuzzification is called defuzzification. The use of FLC produces required output in a linguistic variable. These linguistic variables have to be transformed to crisp output.

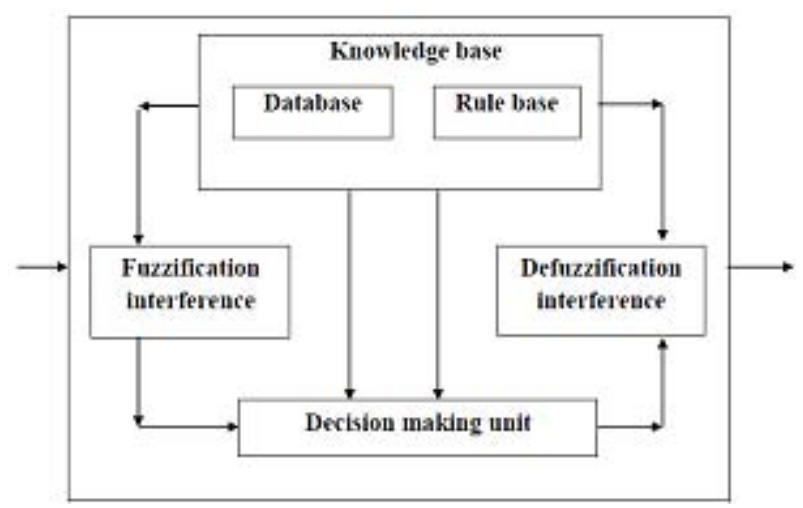

Figure 2: Diagram of fuzzy inference system.

\section{Area Control Error}

Fuzzy logic controller takes the input as ACE and ACE, ACE proportional to frequency deviation and tie line power deviation. So, if ACE settles down properly, all other dynamic parameters are settled down.

\section{Implementation of Membership Function}

Membership Function specifies the degree to which a given input belongs to a set. In literature, many shapes of membership functions are used. Out of these many researchers used triangular type membership function. Further, membership function is segregated into seven linguistic variables:

1. Negative Big (NB)

2. Negative Medium (NM)

3. Negative Small (NS)

4. Zero (ZO)

5. Positive Small (PS)

6. Positive Medium (PM) and

7. Positive Big (PB).

Twenty Five rules are defined for fuzzy rule table between input and output functions. Today control systems are usually described by mathematical models. Usually fuzzy logic control system is created from four major elements presented on Figure 2: fuzzification interface, fuzzy inference engine, fuzzy rule matrix and defuzzification interface.

\section{Problem Formulation}

The aim of LFC is to maintain real power balance in the system through control of system frequency. Whenever the real power demand changes, a frequency change occurs. This frequency error is amplified, mixed and changed to a command signal which is sent to turbine governor. The governor operates to restore the balance between the input and output by changing the turbine output. This method is also referred as Megawatt frequency or Power-frequency (Pf) control. Suppose now that we have an interconnected power system broken into two areas each having one generator. The areas are connected by a single transmission line. The power flow over the transmission line will appear as a positive load to one area and an equal but negative load to the other, or vice versa, depending on the direction of flow. The direction of flow will be dictated by the relative phase angle between the areas, which is determined by the relative speed -deviations in the areas.

\section{Proposed Method}

In this paper an interconnected power system broken into two areas each having one generator. The areas are connected by a single transmission line. The power flow over the transmission line will appear as a positive load to one area and an equal but negative load to the other, or vice versa, depending on the direction of flow. The direction of flow will be dictated by the relative phase angle between the areas, which is determined by the relative speed -deviations in the areas. Consider a three area system interconnected via the tieline and hence at steady state the equation becomes,

$$
\Delta \omega_{1}=\Delta \omega_{2}=\Delta \omega_{3}
$$




\section{International Journal of Science and Research (IJSR) \\ ISSN (Online): 2319-7064}

Index Copernicus Value (2013): 6.14 $\mid$ Impact Factor (2014): 5.611

$$
\begin{gathered}
\frac{d(\Delta \omega 1)}{d t}=\frac{d(\Delta \omega 2)}{d t}=\frac{d(\Delta \omega 3)}{d t} \\
\Delta \omega=\frac{-\Delta \mathrm{P} I 1}{\frac{1}{R_{1}}+\frac{1}{R z}+\frac{1}{R s}+D 1+D 2+D 3}
\end{gathered}
$$

\section{Simulation Results}

In this paper controlling the load frequency of the different areas and particularly 3 areas are taken for the load frequency control. For this controlling purpose, the adaptive fuzzy logic approach is used as a tool and here total 25 fuzzy rules and triangular member function are used. The main purpose of using Fuzzy logic controller is that is very robust and reliable.

$$
A C E_{i}=\sum_{j=1} \Delta P_{i j}+B_{i} \Delta f_{i}
$$

This error is added to the biased frequency error and the ACE. The ACE is communicated with all area generators that are participating in the secondary LFC.

The main objective is now to keep the frequency deviation or change in frequency for change in load of three areas in steady state should be zero.

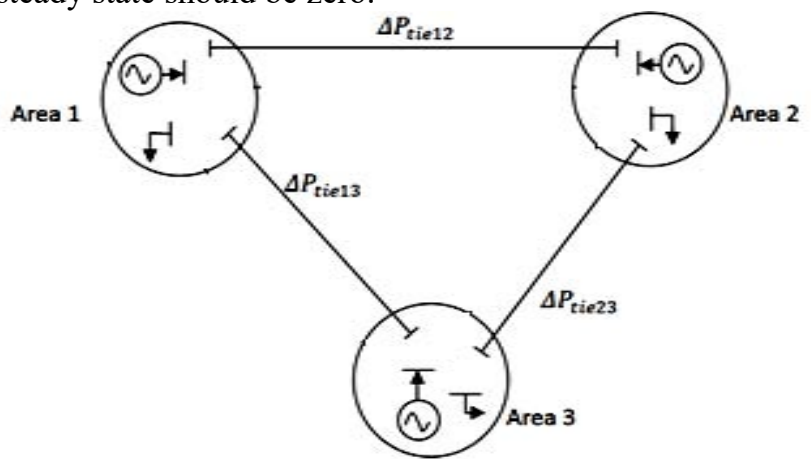

Figure 3: A Three Area Power System

\section{Simulation Model}

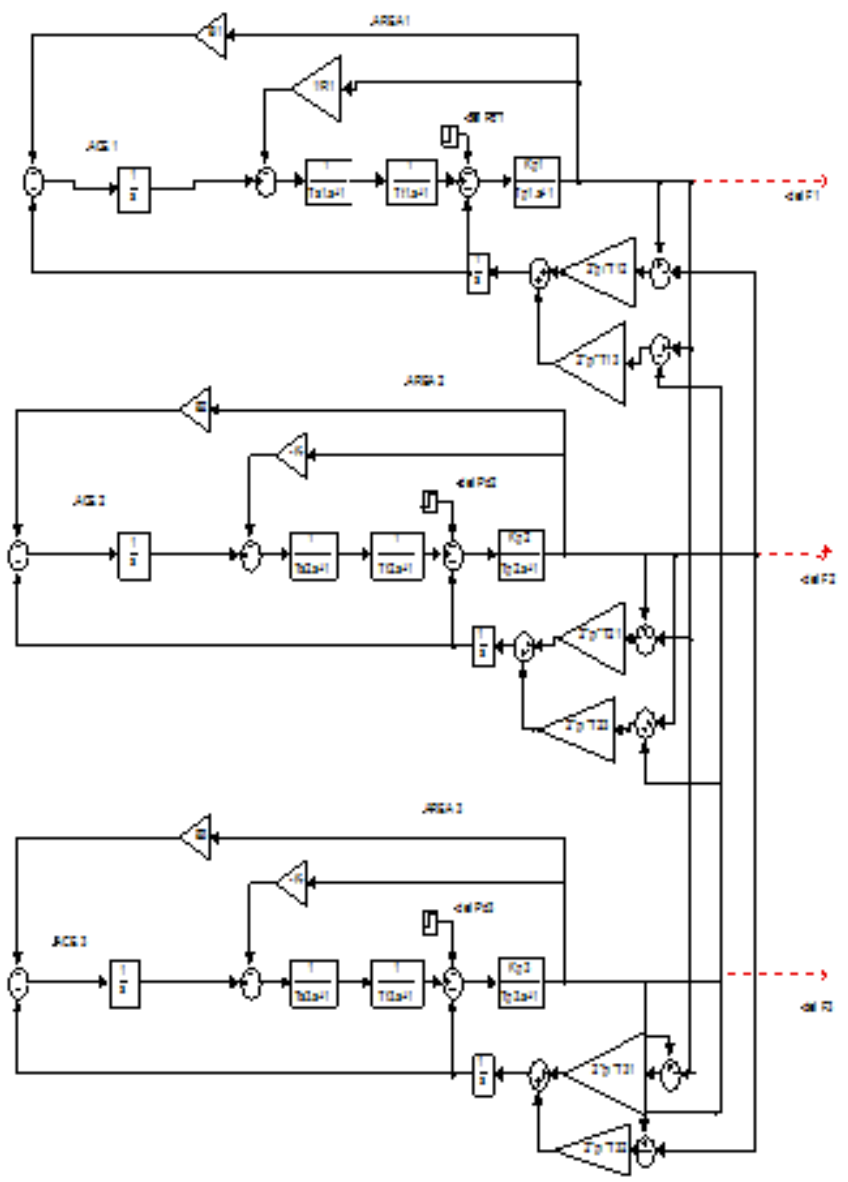

Different frequency deviation with respect to time

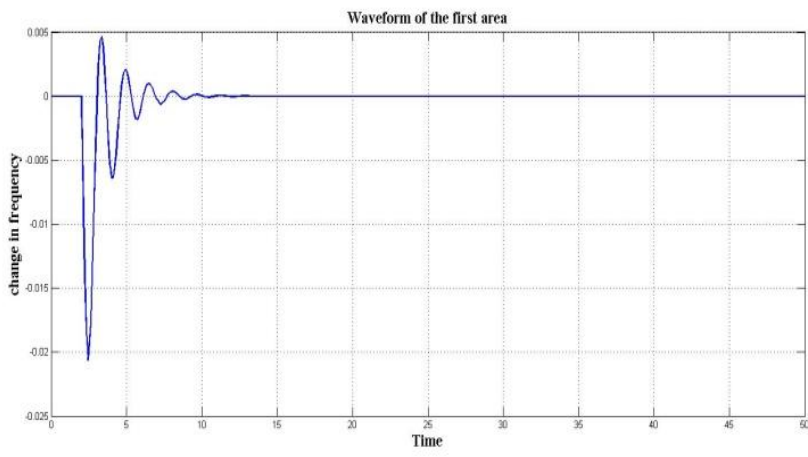

Figure 5: response of three area power system under scenario I

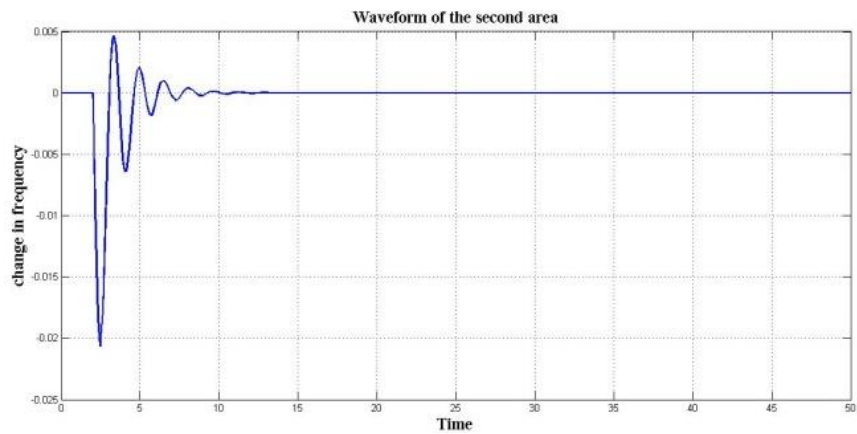

Figure 6: response of three area power system under scenario II

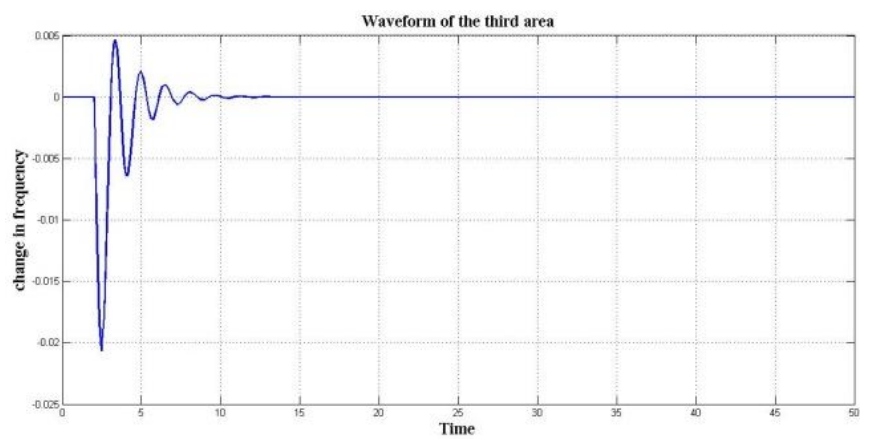

Figure 7: response of three area power system under scenario III 


\section{International Journal of Science and Research (IJSR) \\ ISSN (Online): 2319-7064}

Index Copernicus Value (2013): 6.14 | Impact Factor (2014): 5.611

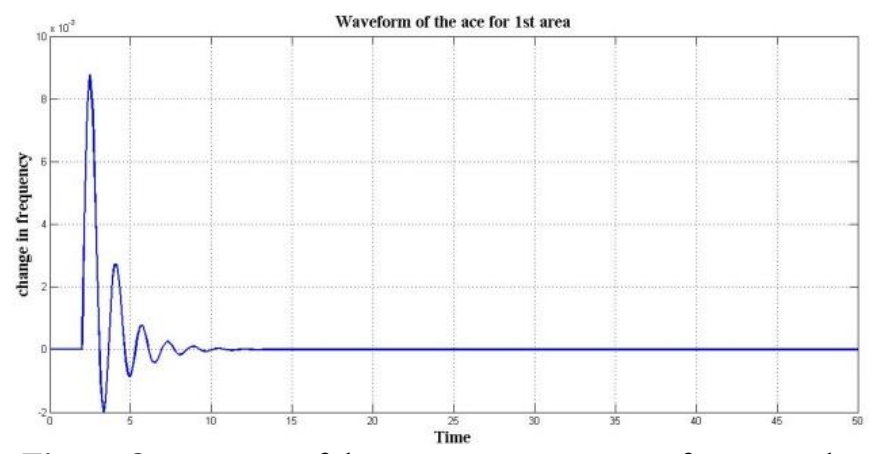

Figure 8: response of three area power system for ace under

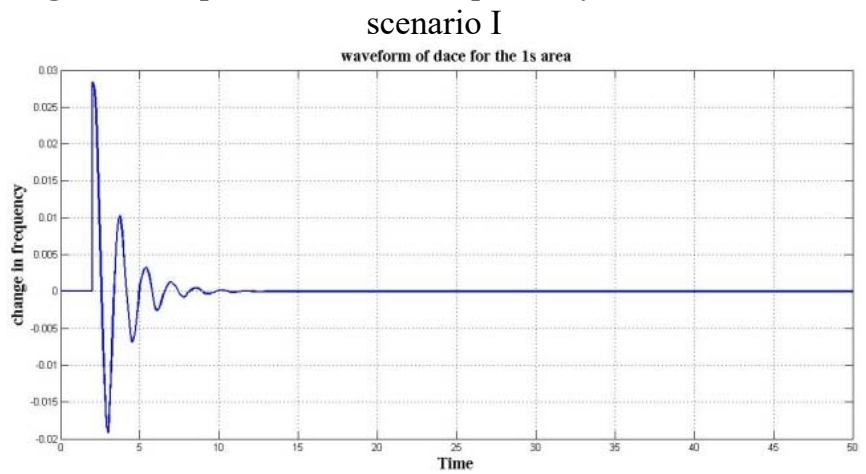

Figure 9: response of three area power system for dace under scenario I

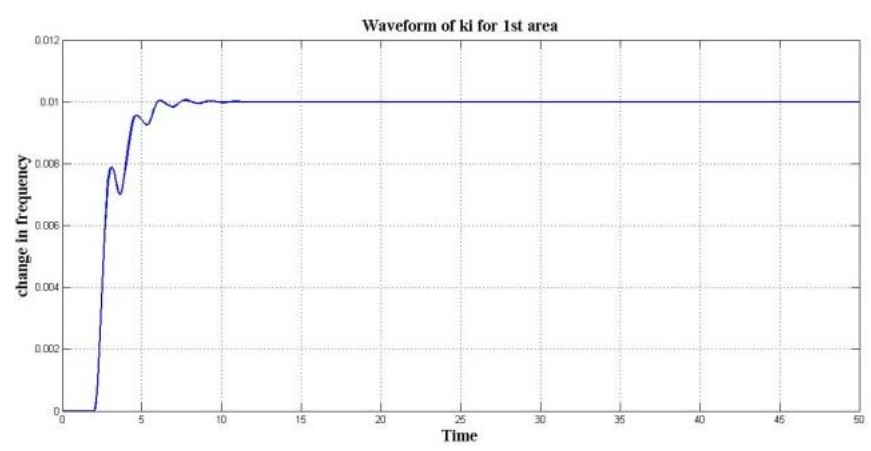

Figure 10: response of three area power system for ki under scenario I

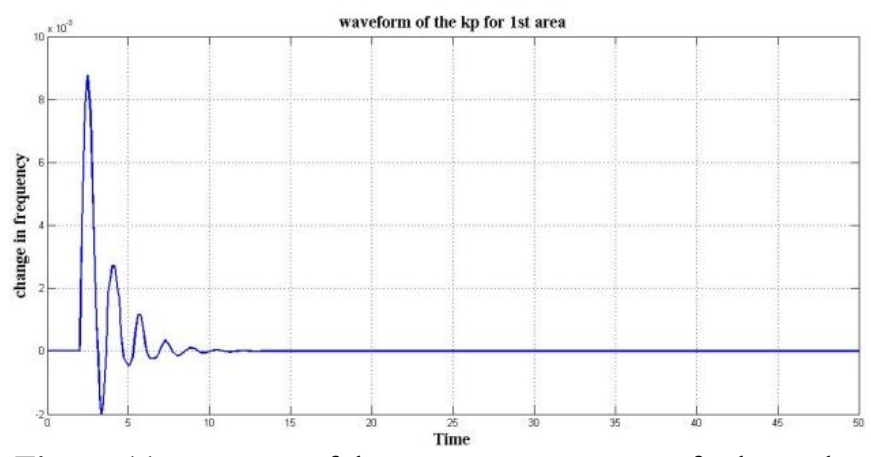

Figure 11: response of three area power system for kp under scenario I

\section{Conclusion}

A fuzzy logic controller (FLC) including conventional integral controller has been proposed to damp out the deviations of the frequency and tie-line power for the interconnected power areas and also to keep the interchanged power at the scheduled value. A fuzzy logic controller (FLC) including conventional integral controller has been proposed to damp out the deviations of the frequency and tie-line power for the interconnected power areas and also to keep the interchanged power at the scheduled value. The proposed FLC is more effective means for improving the dynamic performance of the two power area compared to the conventional integral controller. The proposed FLC is more effective means for improving the dynamic performance of the two power area compared to the conventional integral controller. The proposed FLC controller still achieves good dynamic performance when the GRC is considered and ensures the stability of power areas for all load demand changes.

\section{References}

[1] C. Zhang, L. Jiang, Q. H. Wu, Y. He, and M. Wu, "Delay-dependent robust load frequency control for time delay power systems," IEEE Trans. Power Syst., vol. 28, no. 3, pp. 2192-2201, Aug. 2013.

[2] H. Trinh, T. Fernando, H. H. C. Iu, and K. P. Wong, "Quasi-decen- tralized functional observers for the LFC of interconnected power sys- tems," IEEE Trans. Power Syst., vol. 28, no. 3, pp. 3513-3514, Aug.2013.

[3] S. Saxena and Y. V. Hote, "Load frequency control in power systems via internal model control scheme and model-order reduction," IEEE Trans. Power Syst., vol. 28, no. 3, pp. 2749-2757, Aug. 2013.

[4] H. Bevrani and T. Hiyama, "On load-frequency regulation with time delays: Design and real-time implementation," IEEE Trans. Energy Convers., vol. 24, no. 1, pp. 292-300, Mar. 2009.

[5] H. Shayeghi, H. A. Shayanfar, and A. Jalili, "Load frequency control strategies: A state-of-the-art survey for the researcher," Energy Con-vers. Manag., vol. 50, pp. 344-353, 2009.

[6] Ibraheem, P. Kumar, and D. P. Kothari, "Recent philosophies of au- tomatic generation control strategies in power systems," IEEE Trans. Power Syst., vol. 20, no. 1, pp. 346-357, Feb. 2005.

[7] W. Tan, "Unified tuning of PID load frequency controller for power systems via IMC," IEEE Trans. Power Systems, vol. 25, no. 1, February 2010.

[8] S.K. Aditya, and D.Das,"Load-Frequency Control of an Interconnected Hydro-Thermal Power System with New Area Control Error Considering Battery Energy Storage Facility," International Journal of Energy Research, vol.24, pp.525-538, 2000.

[9] M. U. Usama, D. Kelle, and T. Baldwin, "Utilizing Spinning Reserves as Energy Storage for Renewable Energy Integration," Power Systems Conference, Clemson University, pp.1-5, March 2014.

[10]D. Kottick, M. Blau, and D. Edelstein,"Battery Energy Storage for frequency regulation in an Island Power System", IEEE Transactions on Energy Conversion, vol. 8, no.3, pp.455-459, September 1993.

[11]Prakash K. Ray, Soumya R. Mohanty, Nand Kishor,"Proportional- integral controller based smallsignal analysis of hybrid distributed generation systems," Energy Conversion and Management, vol. 52, no.4, pp.1943-1954, April 2011.

[12]H. Bevrani, F. Habibi, P. Babahajyani, M. Watanabe, and Y. Mitani, "Intelligent Frequency Control in an AC

\section{Volume 4 Issue 12, December 2015}


Microgrid: Online PSO-Based Fuzzy Tuning Approach," IEEE Transactions on Smart Grid, vol. 3, no. 4, pp.1935 - 1944, December 2012.

[13] S. Saxena and Y. V. Hote, "Load frequency control in power systems via internal model control scheme and model-order reduction," IEEE Trans. Power Syst., vol. 28, no. 3, pp. 2749-2757, Aug. 2013.

[14]H. Bevrani and T. Hiyama, "On load-frequency regulation with time delays: Design and real-time implementation," IEEE Trans. Energy Convers., vol. 24, no. 1, pp. 292-300, Mar. 2009.

[15]H. Shayeghi, H. A. Shayanfar, and A. Jalili, "Load frequency control strategies: A state-of-the-art survey for the researcher," Energy Convers. Manag., vol. 50, pp. 344-353, 2009.

[16] Ibraheem, P. Kumar, and D. P. Kothari, "Recent philosophies of automatic generation control strategies in power systems," IEEE Trans. Power Syst., vol. 20, no. 1, pp. 346-357, Feb. 2005.

[17]W. Tan, "Unified tuning of PID load frequency controller for power systems via IMC," IEEE Trans. Power Systems, vol. 25, no. 1, February 2010.

[18] A. Khodabakhshian and M. Edrisi, "A new robust PID load frequency controller," Control Eng. Practice, vol. 16, pp. 1069-1080, 2008.

[19]L.Dong, Y. Zhang, and Z.Gao, "A robust decentralized load frequency controller for interconnected power systems," ISA Trans., vol. 51, pp. 410-419, 2012.

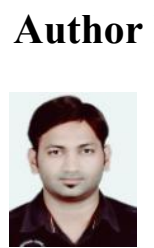

Pradeep Kumar Sahu received the B.E. degree in Electrical and Electronics Engineering from Chhattisgarh Institute Of Technology, Rajnandgaon (CSVTU Bhilai) in 2012 and M.TECH. degree in power electronics from Oriental College of Technology, Bhopal (RGPV Bhopal) in 2015 year.

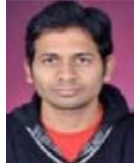

Abhijeet Singh received his B.E. degree in Electcrical and Electronics Engineering from Sagar Institute Of Research \& Technology, Bhopal (RGPV) in 2009 and Master of Enginnering In power electronics from Samrat Ashok Technological Institute Vidisha (M.P.) in 2013. From 2013 to present he is working as an Assistant professor in Electrical and Electronics Department in Oriental College of Technology, Bhopal(M.P.) and his area of interest is in improvement of LFO problems using PSO optimization. 